\title{
BIBLIOTERAPIA: UMA EXPERIÊNCIA DE LER E CONTAR HISTÓRIAS PARA PESSOAS HOSPITALIZADAS
}

Originais recebidos em: 17/02/2012

Aceito para publicação em: 24/02/2012

Leodir Rocha de Oliveira

Universidade Federal de Mato Grosso

leorocha oliveira@hotmail.com

André de Souza Pena

Universidade Federal de Mato Grosso andresouzapena@yahoo.com

Agameton Ramsés Justino Universidade Federal de Mato Grosso agametonrj@yahoo.com.br

Andréa Luciana dos Santos

andrealsfia@ig.com.br

Universidade Federal de Mato Grosso

\section{Resumo}

O trabalho trata de uma análise descritiva de abordagem qualitativa. Avalia o impacto da leitura e contação de histórias mediadas a pessoas hospitalizadas. Averigua os métodos e técnicas de aplicabilidade da leitura terapêutica e avalia as atividades de leitura e contação de histórias desenvolvidas junto ao projeto Patati Patatá Contadores de História no Hospital Regional Irmã Elza Giovanella de Rondonópolis/MT. Os resultados obtidos constatam que as atividades de leitura e contação de histórias proporcionam momentos alegres e descontraídos, transmitindo, assim, conforto e bem-estar às pessoas que se encontram hospitalizadas; tais atividades são, portanto, terapêuticas.

Palavras chave: Biblioterapia. Leitura terapêutica. Ler histórias. Contar histórias.

\section{BIBLIOTHERAPY: AN EXPERIENCE OF READING AND STORYTELLING FOR PEOPLE HOSPITALIZED}

\begin{abstract}
The work is a descriptive analysis, qualitative approach. Assesses the impact of reading and storytelling mediated people hospitalized. Ascertains the applicability of methods and techniques of reading therapy and evaluates the activities of reading and storytelling developed by the project Patati Patata storytellers at the Regional Hospital Sister Elza Giovanella at Rondonopolis, MT. The results conclude that the activities of reading and storytelling, provide moments of joy and relaxed, thereby transmitting, comfort and well being to people who are hospitalized, so they are therapeutic.
\end{abstract}

Keywords: Bibliotherapy. Reading therapy. Read stories. Storytelling.

Extensio: R. Eletr. de Extensão, ISSN 1807-0221 Florianópolis, Ano 8, n. 12, p. 44-60, 2011. 


\section{INTRODUÇÃO}

A estrutura dos hospitais, feita de maneira a facilitar o trabalho dos profissionais e favorecer o tratamento de um grande número de pessoas de forma eficiente, a internação e o tratamento são fatores que causam desconforto, medo e insegurança às pessoas que necessitam ficar internadas (SEITZ, 2006). O fato de uma pessoa ter que passar por longo período num hospital, sem nenhuma ocupação, isolada e afastada do convívio familiar a leva a um estado de estresse, e não só o doente, mas a família ou acompanhante também sofre esse desconforto.

Apesar de toda evolução em que a sociedade vive hoje, percebe-se que, com relação aos hospitais públicos, pouco tem sido feito para que o ambiente hospitalar se torne menos doloroso e mais acolhedor, que seja realmente "hospitaleiro". Conforme Seitz (2006, p. 43), "observa-se que os hospitais, na sua maioria, não oferecem nenhuma atividade de lazer aos seus pacientes $[\ldots] ”$.

Uma das ferramentas que podem ser utilizadas em hospitais para mudar esse quadro é a leitura de livros e a contação histórias. Sendo uma atividade que proporciona bem-estar físico e mental, a leitura é considerada terapêutica, podendo ser praticada em hospitais, a fim de amenizar o sofrimento dos pacientes durante a internação.

Com base em alguns estudos como de Caldim (2001; 2009); Seitz (2006); e Ribeiro (2006), observa-se que a leitura terapêutica vem sendo praticada desde os tempos mais remotos, por diferentes estudiosos e profissionais, para auxiliar no processo de tratamento, recuperação e cura de doenças. Segundo Nascimento e Rosemberg (2007), atualmente essa prática tem sido utilizada em vários campos da saúde e também da educação.

Neste sentido, formulamos a hipótese de que a prática da leitura como atividade terapêutica pode transformar o hospital num ambiente mais alegre, ajudando as pessoas hospitalizadas a superarem o medo, a dor, e a se recuperarem mais rápido. Conforme Ribeiro (2006, p. 113), “a Biblioterapia tem sido uma grande contribuição terapêutica por minimizar o sentimento de angustia, isolamento fragilidade física e emocional decorrentes da internação."

Diante dessa explanação, perguntamos: qual o impacto da leitura terapêutica para a recuperação das pessoas hospitalizadas?

Para podermos responder a essa indagação, determinamos uma proposta de pesquisa voltada para o uso da biblioterapia em hospitais, através da leitura e contação de histórias. Para isso, elegemos como campo de pesquisa o Hospital Regional Irmã Elza Giovanella, de 
Rondonópolis, particularmente as clínicas médica, ortopédica e cirúrgica como unidades para aplicação da leitura.

Refletindo sobre o desconforto causado pelo processo de internação, este trabalho justifica-se pela necessidade de subsídios que favoreçam a promoção da prática biblioterapêutica, por meio de atividades que levem alegria para o ambiente hospitalar, de forma a melhorar a qualidade de vida das pessoas internadas.

\section{REVISÃO DE LITERATURA}

Verifica-se que o tema biblioterapia não é um assunto novo, mas uma temática muito antiga que vem sendo discutida ao longo de muitos anos, e, que desde a antiguidade, suas técnicas têm sido aplicadas no tratamento de diversos tipos de doenças, por profissionais de vários ramos, como médicos, filósofos, bibliotecários, psicólogos enfermeiros e outros.

Seitz (2006) e Ribeiro (2006) relatam que, desde os tempos bem antigos, as pessoas já tinham o hábito de se reunirem entre as famílias para contar histórias, a fim de tornar o tempo mais agradável e como forma de entretenimento para ocupar o tempo ocioso das crianças e adolescentes, até que essa prática foi identificada como instrumento terapêutico, passando a ser utilizada em hospitais, em isolamentos existentes, nas prisões e em outros locais.

Conforme Seitz (2006), entre 1802 e 1853, foram realizadas as primeiras experiências em biblioterapia por médicos americanos, os quais indicavam a leitura de livros, previamente selecionados e apropriados às necessidades individuais de seus pacientes, como parte do tratamento.

De acordo com Ferreira (2003, p. 36), no antigo Egito, o Faraó Rammsés II colocou na frente de sua biblioteca a frase: "Remédios para a alma", e as bibliotecas egípcias, localizadas em templos denominados "casas de vida", eram conhecidas como locais de espiritualidade.

Pode-se dizer que, para os egípcios, a leitura era considerada um ato sagrado, muito além de uma atividade para distração ou passatempo.

Entre os romanos, a leitura, seguida de discussão, das obras de grandes oradores foi recomendada por Aulus Cornelius Celsius como tratamento médico. Os gregos também associavam os livros como forma de tratamento médico e espiritual, ao conceberem suas bibliotecas como "a medicina da alma." (FERREIRA, 2003, p. 36).

Na Primeira Guerra Mundial, bibliotecários da Cruz Vermelha ajudaram a construir bibliotecas nos hospitais do exército, a fim de solucionar problemas pessoais por meio da leitura dirigida (SILVA, 2005). Em 1904, a biblioterapia passou a ser considerada um ramo da Biblioteconomia quando uma bibliotecária se tornou chefe do hospital de Wanderley Extensio: R. Eletr. de Extensão, ISSN 1807-0221 Florianópolis, Ano 8, n. 12, p. 44-60, 2011 
Massachussets e iniciou um programa que envolvia os aspectos psiquiátricos da leitura. (SEITZ, 2006).

Na década de 1930, a biblioterapia passou a ser vista como um campo de pesquisa. Nessa época, Isabel Du Boir e Emma T. Foremman foram duas biblioterapeutas em destaque que se empenharam para que a biblioterapia fosse vista como ciência, e não como arte (RIBEIRO, 2006).

Segundo o médico (BOTSARIS, [200-?]), atualmente a técnica é bem difundida nos Estados Unidos e tem crescido em novos campos como o da psicologia e psiquiatria infantil, tendo revelado resultados extraordinários.

No Brasil, o tema biblioterapia ainda é pouco explorado. De acordo com Almada (2003, apud RIBEIRO, 2006), existem apenas algumas iniciativas pontuais, uma pesquisa aqui outra ali, e alguns grupos de contadores de histórias. Segundo Almada, a prática da biblioterapia no Brasil teve início na década de 1970, por meio de projetos de extensão, entre os quais se destacaram: "O Carro-Biblioteca" e o "Caixas Estantes", ambos da Universidade Federal do Rio Grande do Sul (UFRGS); o projeto de leitura de contos em hospitais, asilos, creches e escolas com o nome "Hora do Conto"; e "O Livro de Cabeceira".

Na década de 1990 houve a criação da "Casa da Leitura", pela Universidade Federal do Rio de Janeiro (UFRJ), em parceria com a Fundação Biblioteca Nacional (FBN). Em 2000 tem início o projeto "Biblioteca Viva em Hospitais", apoiado pelo Ministério da Saúde (MS) e outras experiências de implantação da biblioterapia com crianças em hospitais universitários: Universidade Federal de Santa Catarina (UFSC); Hospital Universitário Infantil Albert Sabin (HIAS), no Ceará, e o Núcleo de Apoio a Criança com Câncer (NAAC), na Paraíba (RIBEIRO, 2006 p. 118).

Percebe-se que a leitura de livros com fins terapêuticos teve seu início nos centros de saúde e nos hospitais, e que atualmente essa prática tem se expandido para outras entidades, como escolas, creches, asilos e centros de reabilitações. De acordo com Ratton (1975, apud BUENO; CALDIM, 2002, p. 159), a biblioterapia é utilizada na "profilaxia, educação, reabilitação e na terapia propriamente dita, em indivíduos nas diversas faixas etárias com doenças físicas ou mentais.”

Seitz (2006), em uma experiência realizada com pacientes internados em clínica médica, observou que a prática biblioterapêutica com pacientes "tornou a hospitalização menos agressiva e dolorosa." Ela ressalta que, quando o paciente lê, ele viaja em um mundo novo de aventuras e fantasias, desligando-se dos problemas, das angustias, do medo e das incertezas, sentindo-se aliviado das tensões emocionais. 
Para a autora, a leitura ajuda o paciente a verbalizar seus problemas. Segundo ela, as fontes de informações como jornais e revistas proporcionam um elo com o mundo exterior, e a possibilidade de manter-se informado faz com que o paciente sinta-se como parte da sociedade, e isso causa estímulo à recuperação. A autora conclui que, em sua experiência, cujo enfoque foi a biblioterapia como fonte de lazer e informação, e no processo de humanização do hospital, oportunizou aos pacientes a vivência de momentos alegres, descontraídos e divertidos, contribuindo significativamente na promoção do bem-estar dos pacientes.

\section{METODOLOGIA}

Este trabalho trata de uma análise descritiva, que consiste em evidenciar as relações existentes entre o fenômeno estudado e outros fatores, as quais podem ser estabelecidas em função de suas propriedades relacionais de causa, efeito e análise de conteúdo, e de abordagem qualitativa, pois buscou entender um fenômeno específico trabalhando com descrições, comparações e interpretações, nas quais o pesquisador pôde interagir com os pesquisados. (MARCONI; LAKATOS, 2006).

Foram utilizadas técnicas de leitura e de contação de histórias com todos os participantes da pesquisa. A coleta de dados foi feita por meio de questionário/entrevista, e, para a quantificação, análise e apresentação dos dados, foram utilizados os programas SPSS e Microsoft Word.

Para a realização deste estudo, escolhemos as clínicas médica, ortopédica e cirúrgica do Hospital Regional Irmã Elza Giovanella de Rondonópolis. Foram entrevistados 20 pacientes, sendo 12 do sexo masculino e 8 do sexo feminino.

Primeiramente foi enviado o projeto de pesquisa à comissão de Ética do Hospital, para ser analisado e dado o consentimento do seu desenvolvimento. Após o consentimento, foi feita, no dia 20 de fevereiro de 2011, uma visita na qual eu me apresentei aos pacientes, falei sobre a pesquisa e lhes perguntei se poderiam responder a um questionário. Isso após as atividades realizadas pelos contadores de histórias do projeto Patati Patatá. Nessa primeira visita, foi aplicado um pré-teste para avaliação do questionário.

Depois de fazer uma revisão do questionário, se deram as visitas nas unidades selecionadas, no período de 12/03/2011 a 28/05/2011. As visitas aconteceram uma vez por semana, entre às $10 \mathrm{~h}$ e $11 \mathrm{~h} 30 \mathrm{~min}$, horário em que os contadores de histórias realizavam suas atividades, os quais entravam em dupla, e um lia um texto e o outro contava causos ou histórias. 
Após a execução das atividades realizadas pela dupla, era aplicado o questionário, com o objetivo de caracterizar os pacientes por idade, sexo, profissão, escolaridade, tipo de leitura preferida por eles e, principalmente, avaliar o impacto da leitura e contação executadas pelos contadores de histórias do projeto Patati Patatá ${ }^{\text {. }}$

Durante as atividades, utilizou-se também a técnica da observação, através da qual foi possível avaliar o interesse e aceitação das atividades, pois, ao entrar em cada enfermaria, notávamos que os pacientes e acompanhantes sentiam-se alegres com a presença dos contadores de histórias, os quais chegavam, se apresentavam e perguntavam se eles queriam ouvir histórias; a resposta era sempre afirmativa, e alguns até comentavam ser um momento agradável.

\section{APRESENTAÇÃO DOS RESULTADOS}

As variáveis utilizadas para traçar o perfil dos pacientes que participaram deste estudo foram pesquisadas e apresentadas em forma de gráficos e tabelas. Com relação à idade dos participantes da pesquisa (Gráfico 1), varia entre 12 e 66 anos, registrando que $20 \%$ têm até 26 anos, $40 \%$ têm entre 27 e 40 anos, enquanto que os demais $40 \%$ possuem mais de 40 anos.

Gráfico 1 - Idade dos pacientes que participaram da pesquisa.

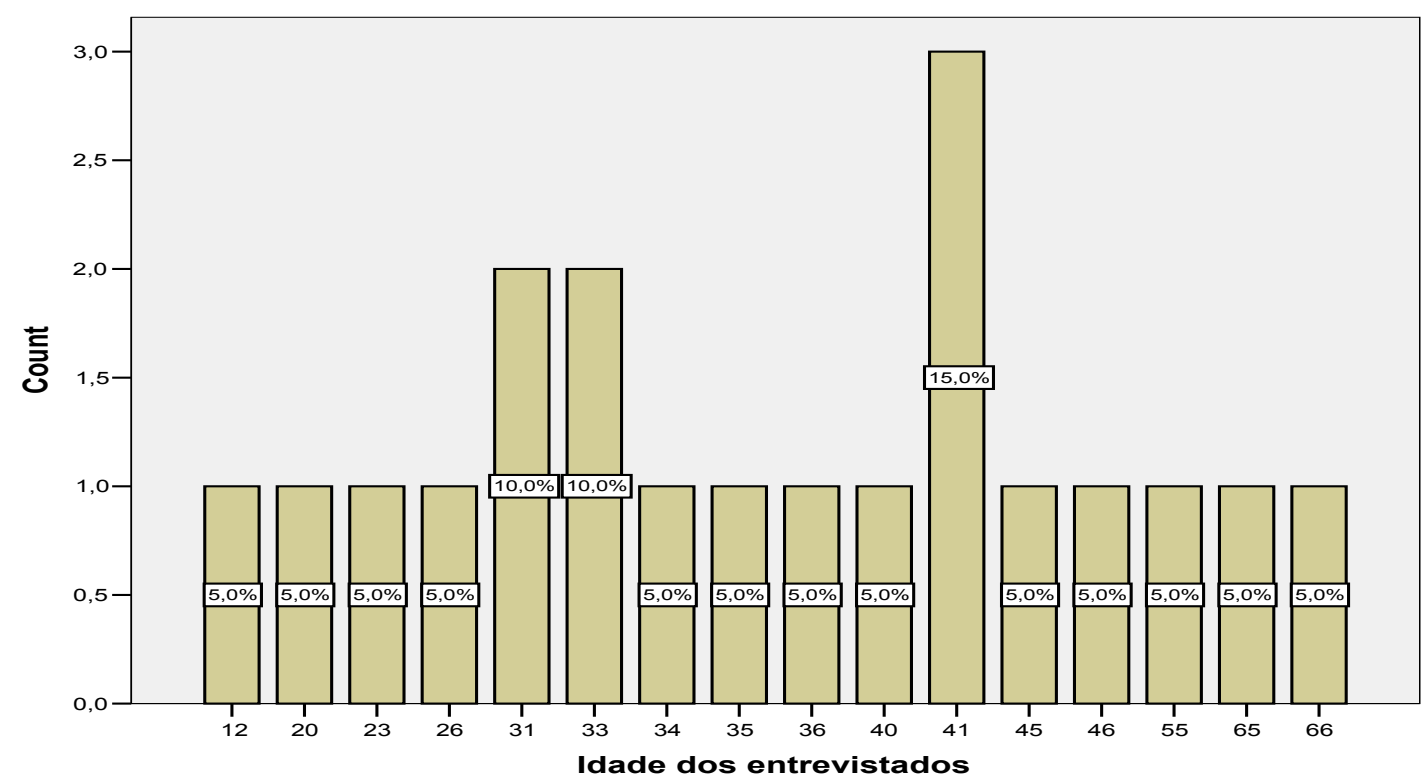

Fonte: Dados da pesquisa, 2011.

\footnotetext{
${ }^{1} \mathrm{O}$ projeto Patati Patata contadores de histórias é a continuação do projeto Biblioteca hospitalar: Leitura no Hospital "Ler, um bem para todos", desenvolvido por funcionários do Hospital Regional, professores e alunos da UFMT. O projeto iniciou-se em 2009, com o intuito de oferecer aos pacientes do Hospital Regional e seus acompanhantes um contato com a literatura, a fim de proporcionar momentos de lazer e entretenimento e, com isso, tirar o interno do foco da doença, amenizando a dor e o estresse, além de promover o incentivo à leitura.
} 
Considera-se que as histórias (contadas ou lidas) são válidas, independente da idade, lembrando que os textos devem ser selecionados conforme o público. No caso de pessoas hospitalizadas, as histórias devem ser alegres, que provoquem risos e descontração.

Uma experiência um pouco parecida foi realizada por 30 alunos do curso de Biblioteconomia da Universidade Federal de Santa Catarina. Os alunos participaram de diversos projetos em diferentes instituições e com públicos de 4 a 95 anos de idade. Conforme o relato de Caldim (2005), a experiência foi bem sucedida, o texto literário lido, contado, dramatizado ou filmado obteve resultado satisfatório, atingiu a mente e o coração dos envolvidos no processo.

Conforme ilustra o Gráfico 2, observou-se que 65\% dos participantes da pesquisa pertencem ao sexo masculino, e 35\%, ao sexo feminino. A porcentagem maior de homens se dá, sobretudo, em relação à unidade ortopédica, que abriga muitas vítimas de acidentes de trânsito.

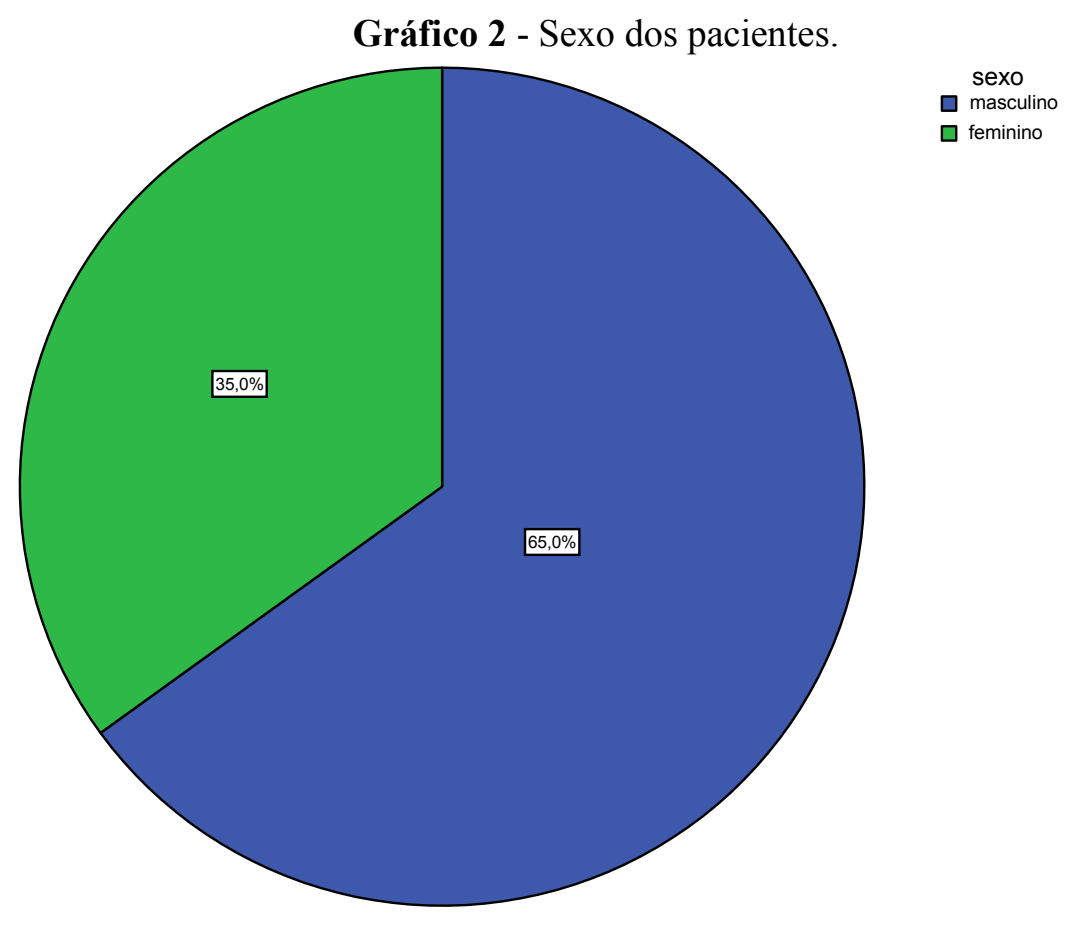

Fonte: Dados da pesquisa, 2011.

A receptividade da história acontece igual, entre homens e mulheres, porém notou-se que os homens apreciam mais as histórias que provocam risos e descontração, como histórias humorísticas, causos, crônicas e piadas, enquanto as mulheres demonstraram atenção em todas as histórias contadas. 
Considera-se, portanto, que as histórias são bem aceitas em qualquer idade por homens e mulheres, adultos, crianças e, principalmente, por pessoas mais idosas, estas adoram ouvir e contar histórias.

Para enfatizar melhor, citamos como exemplo uma paciente com 66 anos de idade que participou das atividades, a qual demonstrou que estava muito contente com a presença dos contadores de histórias e disse que gostava muito de contar histórias antigas para seus filhos e netos, e que esse trabalho de contar histórias é muito importante, pois o hábito de contar histórias entre as famílias, com o tempo, foi sendo substituído pela televisão e hoje pela internet.

Nesse mesmo contexto, percebe-se que as pessoas atualmente estão, na maior parte do tempo, ligadas à televisão e à internet, e, portanto, carentes de histórias, conforme diz Pires (2009, p. 3):

Podemos observar que nesse século que [sic] inicia, já não se valoriza estar com os seus, no aconchego de encontros, para escutar uma história; a maioria das famílias opta pelas imagens da TV, porque [sic] mais fáceis, porque prontas e acabadas. E o que permanece é um estranho e incômodo silêncio, que vai afastando uns dos outros.

Ainda observando o perfil dos entrevistados, conforme o Gráfico 3, verifica-se que o estado civil dos pacientes predominante é o solteiro, com $45 \%$ das observações, $40 \%$ são casados e $15 \%$, separados.

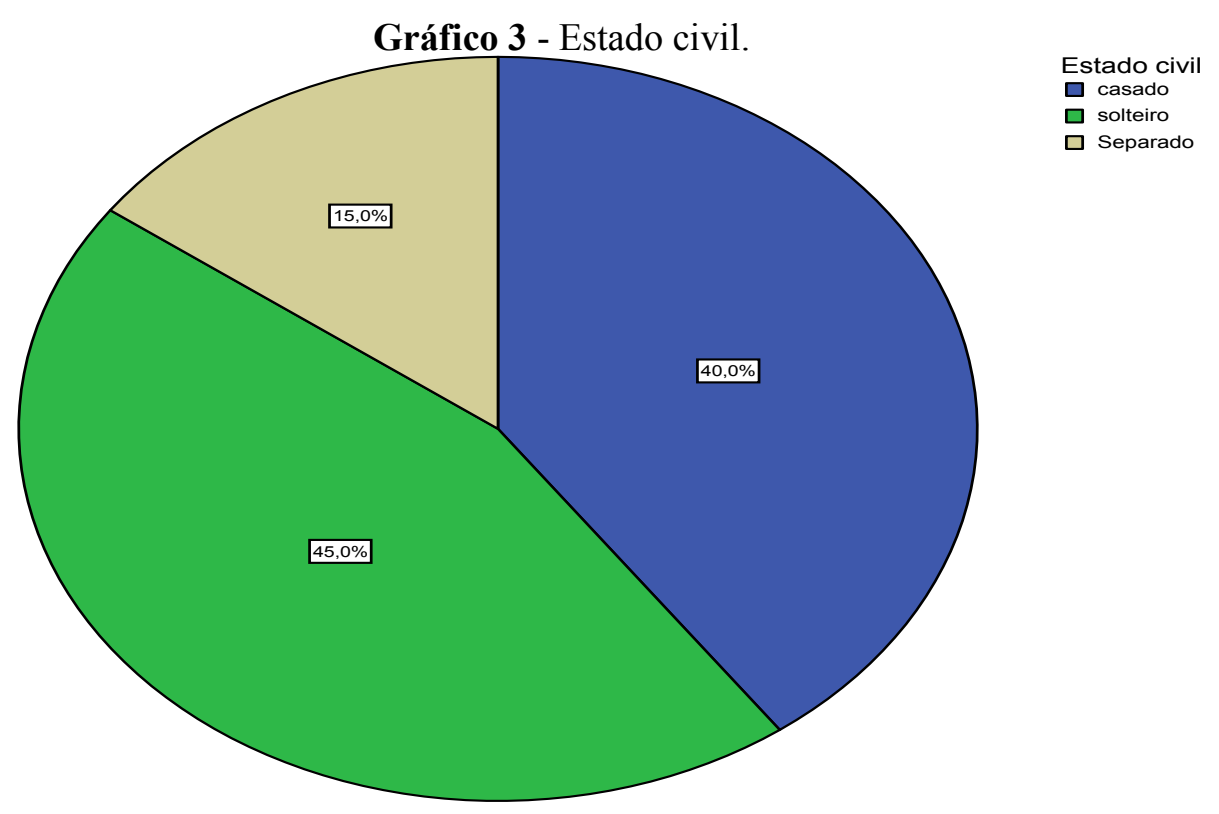

Fonte: Dados da pesquisa 2011. 
No Gráfico 4, identificou-se que a maior porcentagem dos pacientes possui escolaridade baixa: $35 \%$ dos entrevistados têm apenas o ensino fundamental completo e 30\% possuem o ensino fundamental incompleto, seguidos de $15 \%$ com ensino médio incompleto, apenas $10 \%$ com o ensino médio completo e $10 \%$ com ensino superior completo.

Gráfico 4-Nível de escolaridade.

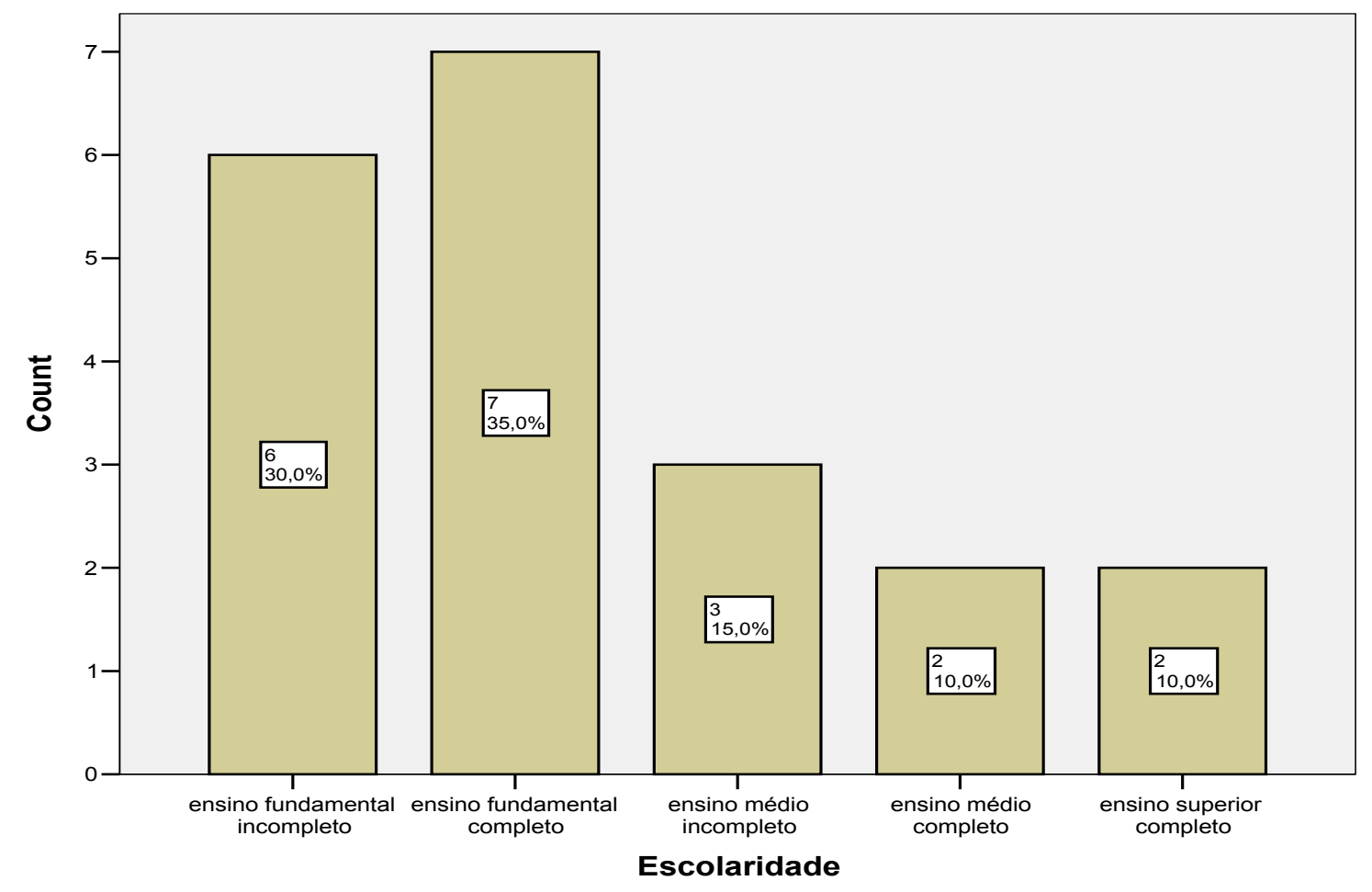

Fonte: Dados da pesquisa, 2011.

De acordo com a análise dos dados, verificou-se que os pacientes são de diversas profissões como: segurança, vendedor, operador de máquinas, construtor civil, pintor, camareiro, fotógrafo e autônomo. Os pacientes entrevistados são de profissões que exigem baixa escolaridade. Essas profissões, em geral, têm uma remuneração menor e, com isso, dependem dos serviços públicos de saúde.

Quanto ao tempo de internação, esse é bem diversificado, variando entre 1 e 210 dias. No Gráfico 5, observa-se o longo período de tempo que alguns pacientes passam num quarto de hospital. Sem uma ocupação, o longo tempo, a dependência de outros e a falta de privacidade leva o indivíduo a um estado de estresse. 
Gráfico 5 - Tempo de internação.

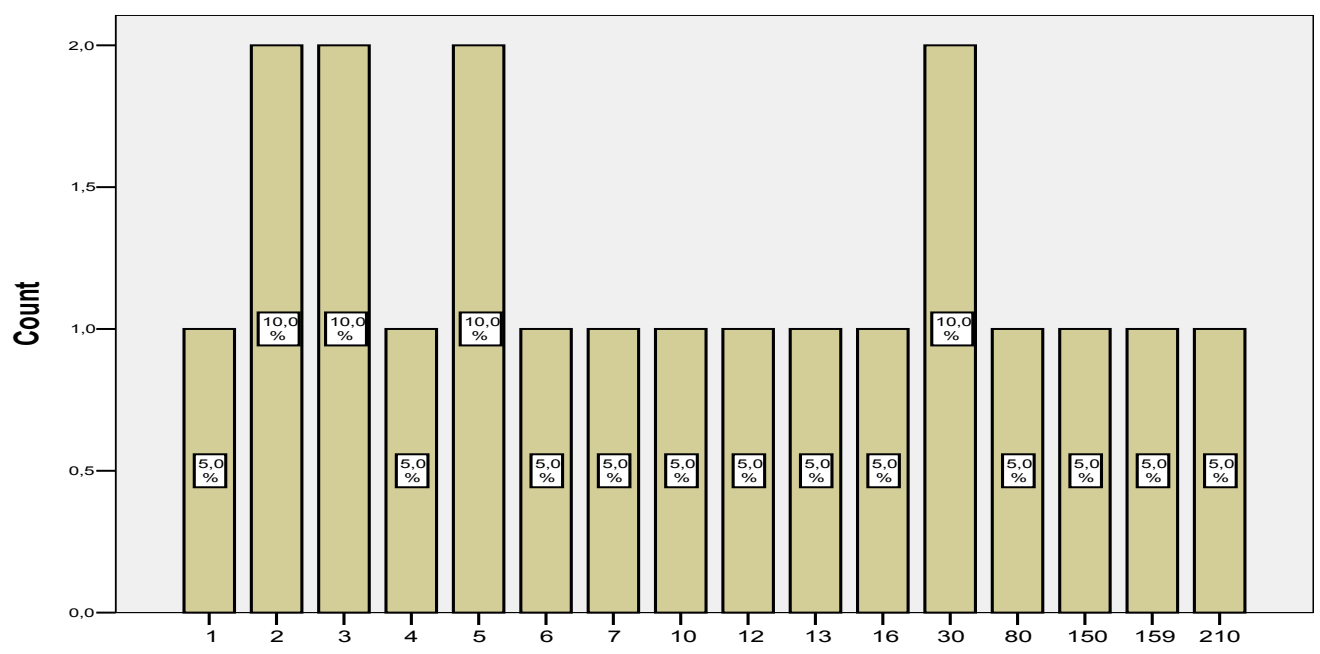

Fonte: Dados da pesquisa, 2011.

Segundo Farias ( apud SEITZ, 2006, p. 42):

Apesar de ser a hospitalização uma experiência vivenciada individualmente, supõe-se que a maioria das pessoas que se hospitalizam, independendo da idade ou do quadro clínico, sejam afetadas pelo estresse. Além do estresse fisiológico produzido pela propria doença, a hospitalização provoca mudanças de ambiente físico e social e, nas atividades diárias do paciente, de modo a afetar todo o seu sistema de vida.

Nesse sentido, a leitura de livros e outras atividades são muito bem aceitas para ocupar o tempo dos internos. Destarte, a biblioteca deveria fazer parte dos compenentes indispensáveis no ambiente hospitalar.

Embora o nível de escolaridade dos entrevistados seja baixo, uma boa parte gosta de ler. Conforme mostra o Gráfico 6, 40\% dos entrevistados gostam mais de ler, enquanto 35\% gostam de ouvir histórias e $25 \%$ gosta tanto de ler quanto de ouvir.

Gráfico 6 - Preferência em ler ou ouvir histórias.

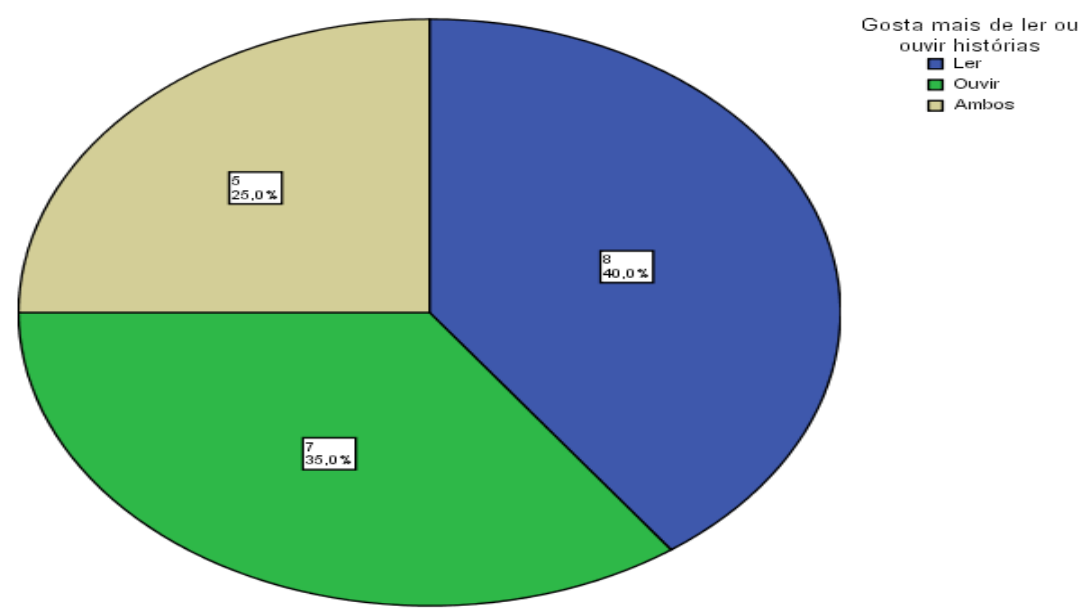

Fonte: Dados da pesquisa, 2011. 
O resultado abaixo confirma a importância das atividades de leitura e contação de histórias, desenvolvidas no ambiente hospitalar, e da disponibilidade de materiais ao alcance das pessoas internadas, dos familiares e dos acompanhantes, pois, além de ocupar-lhes o tempo, afastando-os um pouco de suas angústias e ajudando-os na recuperação de sua saúde, pode também desenvolver o hábito de leitura.

Quanto à forma de leitura (Tabela 1), observa-se que 55\% dos entrevistados gostam mais de ler livros; 20\% gostam de livro, de revista, jornal e gibi; $20 \%$ gostam de revista, jornal e gibi e 5\% não indicaram nenhuma das opções.

Tabela 1 - Gosto da leitura quanto à forma

\begin{tabular}{l|c|c}
\hline Forma de leitura & Número de pacientes & $\%$ \\
\hline Livro & 11 & 55 \\
\hline Livro, revista, jornal, gibi & 4 & 20 \\
\hline Revista, jornal e gibi & 4 & 20 \\
\hline Nenhuma opção & 1 & 5 \\
\hline Total & 20 & 100 \\
\hline
\end{tabular}

Fonte: Dados da pesquisa, 2011.

A leitura é um dos caminhos para o homem conhecer a si mesmo e, por meio dos personagens das histórias, o leitor passa a entender melhor as emoções e os sentimentos, aprende a maneira de agir diante dos problemas.

Conforme Seitz (2006), as diferentes formas de leitura ajudam os pacientes durante a hospitalização, seja como fonte de informação ou como atividade de lazer, podendo trazer resultados surpreendentes.

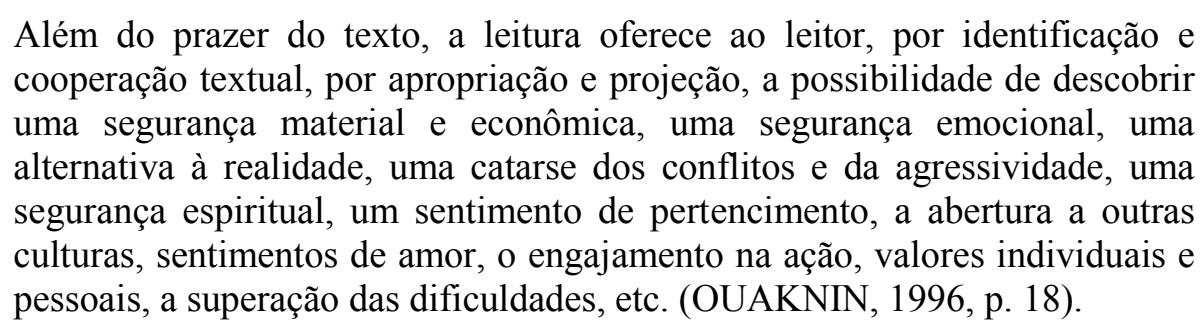

Com relação ao gosto da leitura quanto ao gênero (Tabela 2), 35\% dos entrevistados gostam de ler mais de um gênero (poesia, humor, romance, quadrinhos, contos, crônica, religioso e autoajuda); $20 \%$ gostam de ler romance, $15 \%$ não marcaram nenhuma das opções; 10\% gostam de crônica; $10 \%$ gostam de religioso; $5 \%$ de poesia e 5\% gostam de quadrinhos.

Tabela 2 - Gosto da leitura quanto ao gênero

\begin{tabular}{l|c|c}
\hline \multicolumn{1}{c|}{ Gênero } & Número de pacientes & $\%$ \\
\hline $\begin{array}{l}\text { Poesia, humor, romance, quadrinhos, contos, crônica, } \\
\text { religioso e autoajuda }\end{array}$ & 7 & 35 \\
\hline Romance & 4 & 20 \\
\hline Nenhuma opção & 3 & 15 \\
\hline Crônica & 2 & 10 \\
\hline Religioso & 2 & 10 \\
\hline
\end{tabular}

Extensio: R. Eletr. de Extensão, ISSN 1807-0221 Florianópolis, Ano 8, n. 12, p. 44-60, 2011 


\begin{tabular}{l|c|c}
\hline Poesia & 1 & 5 \\
\hline Quadrinhos & 1 & 5 \\
\hline Total & 20 & 100 \\
\hline
\end{tabular}

Fonte: Dados da pesquisa, 2011.

Para Seitz (2006, p. 60),

A leitura de romance permite ao leitor incorporar o personagem do livro e embarcar em uma viagem repleta de emoções sonhadas e, no retorno desta viagem, esse leitor pode não ser mais o mesmo, pois algo de fundamental sobre seu ser e do seu desejo pode ser revelado e provocado. O leitor pode ainda encontrar personagens com problemas semelhantes aos seus, ou ainda, iguais aos seus, o que pode contribuir lhe dando incentivo para superar seus próprios problemas.

Já Pilagallo (2005) enfatiza a poesia como terapia. De acordo com esse autor, nos Estados Unidos, há mais de vinte anos existe a "Associação Nacional para a Terapia pela Poesia”, entidade na qual o terapeuta trata seus pacientes lendo poesia.

Entretanto, independente do gênero literário, a leitura faz bem à saúde e, ao longo dos tempos, tem se tornado um recurso terapêutico.

A leitura é uma atividade benéfica, sem contra-indicações, recomendada para qualquer idade, inclusive para bebês. Já está comprovada, através da literatura científica, sua função terapêutica no processo de cura. Ao ler, o indivíduo pode buscar informação e atualização em jornais, revistas e livros científicos, ou então, distrair-se, sonhar, rir, imaginar, através das obras de ficção. [...] A literatura tende a trabalhar com os conflitos emocionais, com o humor, com a descontração e com a interpretação dos textos. Já a leitura científica proporciona conhecimento sobre a situação enfrentada. (BENEDETTI, 2008, p. 12).

Quanto a gostar de ouvir a leitura de uma história ou contar uma história sem o uso do livro, o Gráfico 7 mostra que 40\% dos entrevistados gostaram das duas formas de realização das atividades; 30\% gostaram mais da história lida; e 30\% gostaram mais da história contada sem o livro.

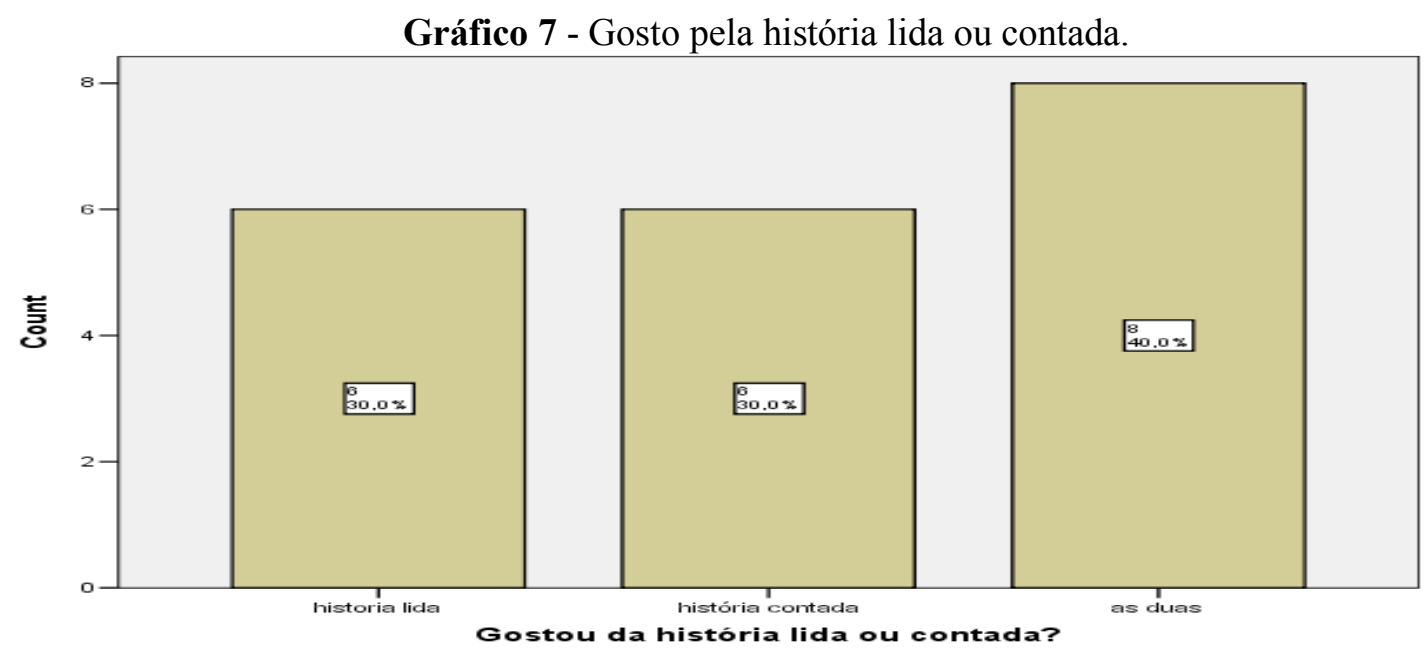

Fonte: Dados da pesquisa, 2011. 
De acordo com Caldim (2009), é fundamental que o leitor ou ouvinte goste do texto ou história e aceite a leitura para que esta funcione como terapia. Quando o ouvinte ou leitor gosta da história, ele se envolve na leitura e se desliga um pouco da rotina do hospital e de seus problemas. Isso pode ser reafirmado com as palavras de pacientes durante a entrevista: "a gente viaja na história”. “[...] fica mais animado, mais confortado, esquece a dor e até que está no hospital".

Ainda sobre o efeito da leitura, Caldim (2001, p. 6) diz o seguinte:

A leitura implica uma interpretação - que é em si mesma uma terapia, posto que evoca a idéia de liberdade - pois permite a atribuição de vários sentidos ao texto. O leitor rejeita o que lhe desgosta e valoriza o que lhe apraz, dando vida e movimento às palavras, numa contestação a caminho já traçado e numa busca de novos caminhos.

Conforme a Tabela 3, 95\% dos entrevistados consideram a leitura importante e gostariam de ter materiais disponíveis no hospital para leitura. Apenas uma paciente respondeu não ser importante. Ela disse que, pelo fato de ser muito agitada, elétrica, não consegue se concentrar para ler no hospital.

Tabela 3 - Gostariam que tivesse materiais no hospital para ler.

\begin{tabular}{|c|c|c|}
\hline & \multicolumn{2}{|c|}{ Gostaria que tivesse materiais no hospital para ler? } \\
\hline & Número de pacientes & $\%$ \\
\hline Sim & 19 & 95 \\
\hline Não & 1 & 5 \\
\hline Total & 20 & 100 \\
\hline
\end{tabular}

Fonte: Dados da pesquisa, 2011.

Esse resultado aponta a biblioteca como um elemento essencial em hopitais. Seitz (2006) descreve que, em muitos países, a biblioteca já é considerada um componente indispensável em hospitais.

Corroborando com Seitz, durante a entrevista, uma paciente comentou que às vezes os parentes levam livros de casa para ela ler, e que no hospital deveria ter materiais de leitura, pois no local não há nada para se distrair.

$\mathrm{Na}$ Tabela 4, verifica-se que 95\% dos entrevistados consideram que é possível esquecer os problemas durante as atividades de leitura e contação de histórias.

Tabela 4 - É possível esquecer os problemas no momento da leitura/contação de histórias.

\begin{tabular}{c|c|c}
\hline \multirow{2}{*}{} & \multicolumn{2}{|c}{ No momento da leitura e contação de histórias é possível esquecer os problemas? } \\
\cline { 2 - 3 } & Quantidade & $\%$ \\
\hline Sim & 19 & 95 \\
Não & 1 & 5 \\
Total & 20 & 100 \\
\hline
\end{tabular}

Fonte: Dados da pesquisa, 2011. 
Reforçando o resultado acima quanto ao momento da atividade de leitura, transcrevemos aqui as palavras ditas durante a entrevista por um paciente que estava internado há sete meses e 10 dias: "Deixa mais tranquilo, evita maus pensamentos tornando-os mais leves, traz alegria e motivação".

As histórias alimentam os bons pensamentos, afastam os pensamentos negativos e fazem a pessoa refletir, o conhecimento adquirido ajuda a pessoa a ter mais paciência, mais calma, ajuda a lidar com seus problemas e a resolvê-los com maior facilidade.

Quanto à intermediação da equipe de contadores de história, todos os participantes da pesquisa responderam que eles conseguem transmitir alegria e conforto durante as atividades, porque só o fato de alguém se dispor a levar uma mensagem de otimismo a pessoas desconhecidas que se encontram num leito de hospital indica uma ação solidária, vontade de compartilhar bons momentos, cuidado amoroso pelo próximo, e isso já é terapêutico.

Durante as visitas, quando os contadores de histórias entravam no quarto e se apresentavam, percebia-se uma alegria estampada no rosto de alguns pacientes, inclusive um paciente se levantou e se sentou na cama para ouvir as histórias. Isso revela a importância das atividades de leitura para as pessoas acamadas. "[...] A gente se sente mais alegre quando uma pessoa chega para conversar". Não só a leitura ou contação de histórias, mas os comentários antes e depois da leitura, o diálogo com o paciente proporcionam bem-estar.

“[...] anima, tira a gente daquele foco ali na dor, porque quando a gente está sozinho fica só pensado no problema”. “[...] sente mais alegre, distrai um pouco".

"[...] a gente se sente melhor, alivia a dor".

Alguns pacientes até contam outras histórias, e em alguns casos todos os que estão internados num mesmo quarto acabam se envolvendo nos comentários e risos. "[...] faz distrair um pouco, sair da rotina”. “[...] acalma, ajuda a ter mais paciência, a gente consegue se envolver na história".

Diante do exposto, os pacientes que participaram da entrevista revelaram que a leitura proporciona: "Um momento de descontração, motivação, alegria, emoção; levanta o astral, toca os sentimentos; transmite conforto, conhecimento e tranquilidade; faz parar de pensar nos problemas; faz refletir, deixa mais animado; alivia a dor, acalma, ajuda a ter mais paciência; transmite paz, bem-estar, motivação; faz esquecer os problemas; é contagiante; diverte um pouco".

Portanto, foi possível perceber, durante as visitas, o quanto é valioso o ato de ler e contar histórias, e que as atividades desenvolvidas pelos integrantes do projeto Patati Patatá 
Contadores de Histórias são muito úteis para as pessoas que se encontram num leito de hospital.

\section{CONSIDERAÇÕES FINAIS}

Os resultados obtidos confirmam o que a literatura tem revelado sobre os benefícios da leitura como terapia. A análise dos dados mostrou ser útil a prática biblioterapêutica com pessoas hospitalizadas, e que as técnicas utilizadas: leitura e contação de histórias são válidas. Com base nas atividades realizadas, não há dúvidas de que a leitura e a contação de histórias proporcionam um momento terapêutico.

É importante frisar que as histórias, contos ou qualquer que seja o gênero literário devem ser alegres e motivacionais, pois não podem ser histórias tristes, mas histórias que levem alegria ao ambiente hospitalar, principalmente as que provoquem o riso, como as crônicas, as histórias engraçadas e de humor, ou as que trazem soluções para os problemas, a fim de tirar o paciente do foco da doença.

Sugerimos a criação de um espaço de leitura dentro do hospital, com estrutura adequada para a realização de atividades biblioterapêuticas em grupos e/ou leitura individual, onde o paciente possa permanecer quando pode andar e sair de seu leito, bem como a disponibilidade de materiais para que os pacientes e acompanhantes possam pegar e ler quando desejarem. Outra sugestão é a inclusão da disciplina "Biblioterapia" nos currículos dos cursos de Biblioteconomia, Letras e Pedagogia, para que os alunos conheçam esse campo de atuação e também sejam capacitados para o desenvolvimento de atividades biblioterapêuticas não só nos hospitais, mas também em outras instituições, como escolas, creches e presídios.

\section{REFERÊNCIAS}

BENEDETTI, Luciane Berto. Biblioterapia para pacientes adultos internados em uma unidade hospitalar: uma proposta de humanização. 2008. 32 f. Projeto de pesquisa (Especialização em Informação Científica e Tecnológica em Saúde) - Instituto de Comunicação e Informação Científica e Tecnológica em Saúde. Porto Alegre, 2008. Disponível em:

$<$ http://arca.icict.fiocruz.br/bitstream/icict/3213/2/Luciane.pdf $>$. Acesso em: 3 nov. 2011.

BOTSARIS, Alex. Biblioterapia: por que hábito de leitura faz bem à saúde. [S.1: s.n.], [200-?]. Disponível em: < http://www2.uol.com.br/vyaestelar/frame.htm?vya>. Acesso em: 03 nov. 2011. 
BUENO, Silvana Beatriz; Caldim, CLARICE, Fortkamp. A Aplicação da Biblioterapia em crianças enfermas. Revista ACB: Biblioteconomia em Santa Catarina, v. 7, n. 1, 2002. Disponível em: <revista.acbsc.org.br/index.php/racb/article/download/372/446>. Acesso em: 12 mar. 2010.

CALDIM, Clarice Fortkamp. A Leitura como Função terapêutica: Biblioterapia. Encontros Bibli. R. Biblioteconomia e Ciência da Informação. Florianópolis, n.12, dez. 2001. Disponível em: <www.periodicos.ufsc.br/index.php/eb/article/viewFile/36/5200>. Acesso em: 12 mar. 2010.

CALDIM, Clarice Fortkamp. Biblioterapia: Atividades de leitura desenvolvidas por acadêmicos do Curso de Biblioteconomia da Universidade Federal de Santa Catarina. Biblios. Revista Electrônica de Bibliotecología, Archivologia y Museologia. Universidade Peruana de Ciências aplicadas: Lima, Peru, v.6. n. 21-22, ago. 2005. disponível em: <http://redalyc.uaemex.mx/pdf/161/16102202.pdf >. Acesso em:12 mar. 2010.

CALDIM, Clarice Fortkamp. Leitura e terapia. 2009, 216 f. Tese (Doutorado em literatura)- UFSC: Florianópolis, 2009. Disponível em: <http://www.tede.ufsc.br/teses/PLIT0342-T.pdf >. Acesso em: 25 Jul. 2010.

FERREIRA, Danielle Thiago. Biblioterapia: uma prática para o desenvolvimento pessoal. Educação temática digital. Campinas, SP, 2003. v.4 n.2, p.35-47. jun. 2003. disponível em:

$<$ http://www.bibli.fae.unicamp.br> Acesso em: 15 mar. 2010.

MARCONI, Marina de Andrade; LAKATOS, Eva Maria. Fundamentos de metodologia cientifica. São Paulo: Atlas, 2006.

NASCIMENTO, Geovana Mascarenhas do; ROSENBERGUE, Dulcinea Sarmento. A Biblioterapia no tratamento de enfermos hospitalizados. Espírito Santo: UFES, 2007. Disponível em: <www.uel.br/revistas/uel/index.php/informacao/article/viewFile/.../1496> . Acesso em: 15 mar. 2010.

PARDINI, M. A. Biblioterapia! Encontro perfeito entre o bibliotecário, o livro e o leitor no processo de cura através da leitura. Estamos preparados para essa realidade? In: SEMINÁRIO NACIONAL DE BIBLIOTECAS UNIVERSITÁRIAS. 12, 2002, Recife. Anais... Recife: UFPE, 2002. Disponível em: $<$ http://www.sibi.ufrj.br/snbu/snbu2002/oralpdf/87.a.pdf>. Acesso em: 15 mar.2010.

PEREIRA, Marília Mesquita Guedes. Biblioterapia: proposta de um programa de leitura para portadores de deficiência visual em Bibliotecas Públicas. João Pessoa: EDUFPB, 1996.

PILAGALLO, Oscar. Ler e crer faz bem à saúde: poesia e fé podem minimizar a dor ou até curar. 2005. Disponível em:

$<$ http://www2.uol.com.br/entrelivros/noticias/ler_e_crer_fazem_bem_a_saude.html $>$. Acesso em: 25 out. 2011.

PIRES, Elmita Simonetti. Literatura, leitura e a arte de contar histórias. In: CONGRESSO DE LEITURA DO BRASIL, 17., 2009, Campinas. Anais..., Campinas, SP: ALB, 2009. Disponível em:< http://alb.com.br/arquivo-morto/edicoes_anteriores/anais17/txtcompletos/sem15/COLE_505.pdf $>$. Acesso em: 22 maio 2010.

OUAKNIN, Marc-Alain. Biblioterapia. São Paulo: Loyola, 1996.

RIBEIRO, Gizele. Biblioterapia: uma proposta para adolescentes internados em enfermarias de hospitais públicos. Rev. Digital de Biblioteconomia e Ciência da Informação. Campinas, v. 3 n. 2, p. 112-126, jan/jun. 2006. Disponível em:

<www.sbu.unicamp.br/seer/ojs/include/getdoc.php?id=265>. Acesso em: 15 mar. 2010. 
ROSA, Aparecida Luciene Resende. As cartas de Ana Cristina Sésar: uma contribuição para a Biblioterapia. 2006. 83f. Dissertação (Mestrado em Letras)-Universidade Vale do Rio Verde de Três Corações, Três Corações, MG, 2006. Disponível em:

<www.unincor.br//aparecida\%20luciene\%20resende\%20rosa.pdf >. Acesso em: 29 mar. 2010.

SEITZ, Eva Maria. Biblioterapia: Uma Experiência com Pacientes Internados em Clinica Médica. Florianópolis: Habitus, 2006.

SILVA, Alexandre Magno da. Características de produção documental sobre biblioterapia no Brasil. 2005. 121 f. Dissertação (Mestrado em Psicologia). UFSC: Florianópolis, 2005. Disponível em: <http://www.tede.ufsc.br/teses/PPSI0170.pdf>. Acesso em: 14 maio. 2010. 